\title{
A LÍNGUA BRASILEIRA DE SINAIS COMO DISCIPLINA OBRIGATÓRIA NA GRADUAÇÃO EM ENFERMAGEM: opiniões dos discentes
}

\section{THE BRAZILIAN SIGN LANGUAGE AS A MANDATORY SUBJECT IN NURSING GRADUATION: students' opinions}

\section{LA LENGUA BRASILEÑA DE SEÑALES COMO DISCIPLINA OBLIGATORIA EN LA GRADUACIÓN EN ENFERMERÍA: opiniones de los discentes}

\author{
Reinaldo dos Santos Moura ${ }^{1}$, Francisco Joilsom Carvalho Saraiva ${ }^{2}$, Vívian Mayara da Silva Barbosa ${ }^{3}$, Gidelson \\ Gabriel Gomes ${ }^{4}$, Ana Carolina do Nascimento Calles ${ }^{5}$, José Alfredo dos Santos Júnior ${ }^{6}$
}

\section{RESUMO}

Objetivo: descrever as opiniões dos graduandos em enfermagem acerca da Disciplina obrigatória de Libras durante a sua formação. Método: estudo de abordagem quantitativodescritiva e transversal, desenvolvido com estudantes de enfermagem $\left(1^{\circ}, 2^{\circ}, 7^{\circ}\right.$ e $8^{\circ}$ períodos $)$ de uma Instituição de Ensino Superior. Para coleta dos dados, utilizou-se um questionário padronizado. Resultados: participaram da pesquisa 119 graduandos em enfermagem e, entre os entrevistados, $76 \%$ não conheciam Libras antes de estudar na faculdade; $99 \%$ acham a Disciplina de Libras importante e relevante; cerca de $87 \%$ explicitam que as aulas são proveitosas, $67 \%$ pretendem se especializar em Libras e $94 \%$ solicitam estágios com os surdos. Conclusão: o instrumento Libras, ao ser ofertado quanto disciplina no curso de graduação em Enfermagem, obteve impacto positivo na perspectiva dos graduandos.

Descritores: Educação Superior; Enfermagem; Barreiras de Comunicação; Acesso aos Serviços de Saúde; Capacitação de Recursos Humanos em Saúde.

\begin{abstract}
Objective: to describe Nursing undergraduate students' opinions about the compulsory BSL subject during their formation. Method: quantitative-descriptive and cross-sectional field research, developed with a sample of 119 nursing undergraduate students from a Higher Education Institution, applying a closed questionnaire and using descriptive statistics. The study complied with ethical principles, opinion No. 1.684.722. Results: among the interviewees, $76 \%$ did not know BSL before studying in college; 99\% consider the BSL Subject important and relevant; about $87 \%$ state that classes are profitable, $67 \%$ intend to specialize in BSL and $94 \%$ request internships with the deaf. Conclusion: the BSL instrument, when offered as a subject of undergraduate nursing course, had a positive impact from students' perspective.
\end{abstract}

Descriptors: Higher Education; Nursing; Communication Barriers; Access to Health Services; Health Human Resources Qualification.

\footnotetext{
${ }^{1}$ Enfermeiro, Especialista em UTI e Docente do Centro Profissionalizante Santa Juliana.

${ }^{2}$ Enfermeiro. (Estácio FAL). Pós graduando em Enfermagem Obstetrícia pela FIP Patos.

${ }^{3}$ Enfermeira. Mestranda pelo PPGENF/UFAL.

${ }^{4}$ Mestre em Ensino na Saúde. Especialista em Auditoria em Serviços de Saúde. Enfermeiro. Docente da pós-graduação na FIP/CEPEM e IDE Cursos/Redentor. Docente do curso de enfermagem do UNIFAVIP/DeVry University, Brasil.

${ }^{5}$ Doutora em Biotecnologia em Saúde. Mestre em Nutrição Humana. Graduação em Fisioterapia. Especialista em Fisioterapia Respiratória e Intensiva. Pós-graduada em Fisiologia do Esforço aplicada ao Desempenho a Saúde e Fisioterapia na UTI. Coordenadora Adjunta do curso de Medicina, professora Adjunta da UNIT. Diretora da Regional Alagoas da ASSOBRAFIR.

${ }^{6}$ Graduação em farmácia-Bioquímica. Graduação em Ciências Biológicas. Mestrado em Ciências da Saúde. Professor do Centro universitário CESMAC.
} 


\section{RESUMEN}

Objetivo: describir las opiniones de los bachilleres de enfermería acerca de la Disciplina de Libras obligatoria durante su formación. Método: investigación de campo cuantitativodescriptiva y transversal. Se utilizó una muestra de 119 estudiantes de enfermería de una determinada Institución de Enseñanza Superior, aplicándose un cuestionario cerrado y utilizándose la estadística descriptiva. Los principios éticos fueron respetados, con opinión n.1.684.722. Resultados: entre los entrevistados, $76 \%$ no conocían Libras antes de estudiar en la universidad; 99\% consideran la Disciplina de Libras importante y relevante; cerca de $87 \%$ explicitan que las clases son provechosas, 67\% pretenden especializarse en Libras y $94 \%$ solicitan pasantías con los sordos. Conclusión: el instrumento Libras, al ser ofertado como disciplina del curso de graduación en Enfermería, obtuvo un impacto positivo en la perspectiva de los bachilleres.

Descriptores: Enseñanza Superior; Enfermería; Barreras de comunicación; Acceso a los Servicios de Salud; Capacitación de Recursos Humanos en Salud.

\section{INTRODUÇÃO}

O acesso de uma pessoa com deficiência auditiva aos serviços públicos de saúde é assegurado pela legislação brasileira através da Constituição Federal de 1988 no artigo $196^{\circ}$ e na Lei orgânica de saúde 8080 de 1990 no artigo $7^{\circ}$, os quais definem universalidade e igualdade nas ações e serviços de saúde. ${ }^{1,2}$

Sendo assim, este estudo tem como objeto a opinião dos graduandos em Enfermagem que cursaram a disciplina de Língua Brasileira de Sinais (Libras) em uma Instituição de Ensino Superior (IES) de Maceió, Alagoas. A perspectiva desta IES em manter essa disciplina de forma obrigatória na matriz curricular visa a promover uma assistência à saúde do surdo como um fator sócio-inclusivo.

Porém, é possível observar que existe

um distanciamento entre este direito garantido e a real situação prática

encontrada pelos cidadãos surdos no acesso aos serviços de saúde ${ }^{3,4}$, expresso principalmente por dificuldades na comunicação. ${ }^{3-5} \mathrm{O}$ atendimento à pessoa surda é um desafio para os profissionais da saúde e para o próprio surdo. ${ }^{6}$

Assim, as barreiras de comunicação encontradas pelos profissionais de saúde e pacientes surdos são prejudiciais ao diagnóstico e tratamento das doenças desses pacientes. $^{7,8} \mathrm{Na}$ assistência em saúde, somente a partir de uma boa comunicação estabelecida, poderão ser identificadas e resolvidas as necessidades dos pacientes de forma humanizada e integral. ${ }^{9}$

Para a equipe de enfermagem, a comunicação com estes pacientes será prejudicada, no que diz respeito à troca de informações, faltando habilidades em transmitir informações sobre sua saúde ${ }^{8}$, razão pela qual utilizam estratégias como leitura labial, mímicas e a intermediação de 
acompanhantes $^{3}, \quad$ prejudicando a confidencialidade da consulta.

Isto ocorre por falta de conhecimento da Libras $^{3}$, que foi regulamentada como Língua Oficial da pessoa surda no Brasil desde 2002 através das Leis 10.436 e 10.098. ${ }^{10,11}$ Trata-se de um sistema linguístico utilizado pela comunidade surda brasileira, de modalidade gestual-visual e com estrutura gramatical independente da Língua portuguesa falada no Brasil. ${ }^{12}$

O não conhecimento da Libras por parte dos enfermeiros é um problema atual oriundo desde a sua formação profissional, com a não obrigatoriedade da oferta desta disciplina na grade curricular do curso de Bacharelado em Enfermagem, em razão de, no Brasil, ser legalizada como disciplina optativa para esta graduação, conforme o Decreto 5.626 de 2005:

"Art. 3- A Libras deve ser inserida como disciplina curricular obrigatória nos cursos de formação de professores para o exercício do magistério, em nível médio e superior, e nos cursos de Fonoaudiologia, de instituições de ensino, públicas e privadas, do sistema federal de ensino e dos sistemas de ensino dos Estados, do Distrito Federal e dos Municípios. (...) $\S 2^{\circ}$ A Libras constituir-se-á em disciplina curricular optativa nos demais cursos de educação superior e na educação profissional, a partir de um ano da publicação deste Decreto. $^{13}$,'

É importante destacar que, em nenhuma legislação, é assegurado o direito de escolher não atender um surdo. Cabe, assim, aos profissionais, a obrigação de se instruírem ${ }^{7}$, buscando capacitações, a fim de melhorar sua conduta frente a um possível atendimento a uma pessoa surda. ${ }^{12}$ Vale ressaltar as instituições que adotam Libras como componente curricular aliada à contratação de profissionais qualificados para o atendimento integral e equânime a todos os cidadãos. ${ }^{9}$ Assim, a questão linguística, ainda que central, não pode suprimir as liberdades individuais ou diferenças, devendo, portanto, reconhecêlas, considerá-las e valorizá-las no acesso aos direitos civis, sociais e políticos. ${ }^{14}$

Apresenta-se como justificativa que a comunicação com os surdos ainda é uma problemática importante no seu acesso aos serviços de saúde, limitando o atendimento, representando um risco para assistência à saúde pela ausência da Libras durante a formação acadêmica do profissional de saúde. Vê-se a necessidade da implantação da disciplina de Libras na matriz curricular dos cursos de graduação em enfermagem e da saúde, como passo inicial ao fornecimento de um atendimento digno e humanizado para as pessoas surdas, ressaltando, assim, a importância do estudo.

Constata-se a escassez de publicações acerca desta temática no recorte geográfico em apreço e destaca-se o pioneirismo da IES por disponibilizar a disciplina de forma eletiva. Baseado no que foi abordado até então, foi elaborada a questão que melhor norteou o estudo: Como opinam os graduandos em enfermagem sobre o suporte 
de conhecimento adquirido através da oferta de Libras enquanto disciplina obrigatória durante a sua formação em uma IES privada de Alagoas?

A fim de responder tal questionamento, esta pesquisa buscou descrever a opinião de graduandos em enfermagem acerca da oferta de Libras enquanto disciplina obrigatória em sua formação.

\section{MÉTODO}

Estudo de abordagem quantitativodescritiva e transversal. Foi desenvolvido em uma Instituição de Ensino Superior (IES) privada de Maceió, Alagoas, que oferta a disciplina de Libras em sua matriz curricular de forma obrigatória para os Bacharelandos de Enfermagem. A população do estudo foi composta por esses bacharelandos do $1^{\circ}, 2^{\circ}, 7^{\circ}$ e $8^{\circ}$ períodos do curso de graduação, distribuindo-se em ordem crescente em Libras/períodos I, II, III e IV, sendo em número total de 180 discentes.

A amostra foi calculada maximizando a variância de $50 \%$, ou seja, visto que não existem informações prévias a respeito destas estimativas, foi considerada uma confiança de $99 \%$ e um erro máximo de $5 \%$. Obteve-se um número de 119 possíveis participantes da pesquisa, em seis turmas, respeitando, ainda, os critérios eleitos de inclusão: Graduando em Enfermagem de 2016.1 da IES, que cursaram a disciplina de Libras, com idade mínima de 18 anos e que assinaram o Termo de Consentimento Livre e Esclarecido (TCLE) e critérios de exclusão: Graduandos em Enfermagem não matriculados em 2016.2 da IES.

O instrumento de coleta dos dados foi desenvolvido pela equipe de pesquisa, composto por um questionário dividido em duas partes com perguntas fechadas: sete sobre o perfil socioeconômico e a outra com interrogações acerca do objeto de estudo. Foram respeitados os princípios éticos da Resolução n $n^{\circ}$. 466/2012 do Conselho Nacional de Saúde (CNS), que regulamenta as pesquisas com seres humanos, sendo o projeto aprovado sob o parecer $n^{\circ} .1 .684 .722$ e o CAAE: 57020416.0.0000.5013, através da Plataforma Brasil e do Comitê de Ética e Pesquisa da Universidade Federal de Alagoas.

Após essa aprovação, nos meses de agosto a setembro de 2016, foi realizada a coleta dos dados na IES, nos horários dos intervalos das aulas, de segunda à sexta, nos turnos matutino e noturno, sendo criado para os dados quantitativos um banco de dados, baseado nas variáveis eleitas (sexo, logradouro, escolaridade, faixa etária, turno de estudo, vínculo empregatício e estudantil, estado civil, Libras estudadas [I, II, III e IV]) no Microsoft Excel $2010^{\circledR}$ com 
a aplicação da estatística descritivapercentil, em tabelas e gráficos.

\section{RESULTADOS}

Abordou-se um número de 119

Graduandos em Enfermagem, obedecendo as variáveis e os critérios eleitos na pesquisa.

A Tabela 01 foi agrupada com as características socioeconômicas dos sujeitos da pesquisa e observou-se uma predominância em relação ao sexo feminino (96\%), à faixa etária de 18 a 45 anos (97\%). Enfatiza-se que a IES não funciona no turno vespertino, e percebe-se que a maioria dos graduandos estava matriculada no turno noturno (55\%), possuía vínculo empregatício (52\%) e cursava o $2^{\circ}$ período, equivalente ao II módulo da disciplina de Libras (35\%).

Tabela 01 - Características da Amostra, Maceió - AL, Brasil

\begin{tabular}{|c|c|c|}
\hline Variável & $\mathbf{N}^{\circ}$ & $\%$ \\
\hline \multicolumn{3}{|l|}{ Sexo } \\
\hline Masculino & 05 & 04 \\
\hline Feminino & 114 & 96 \\
\hline \multicolumn{3}{|l|}{ Faixa etária } \\
\hline 18 a 25 anos & 49 & 41 \\
\hline 26 a 35 anos & 49 & 41 \\
\hline 36 a 45 anos & 18 & 15 \\
\hline 46 a 55 anos & 03 & 03 \\
\hline$>56$ anos & 00 & 00 \\
\hline \multicolumn{3}{|c|}{ Turno de estudo } \\
\hline Matutino & 53 & 45 \\
\hline Noturno & 66 & 55 \\
\hline \multicolumn{3}{|c|}{ Vínculo empregatício } \\
\hline $\operatorname{Sim}$ & 62 & 52 \\
\hline Não & 57 & 48 \\
\hline \multicolumn{3}{|c|}{ Período/Disciplina } \\
\hline 1\%/Libras I & 24 & 20 \\
\hline $2^{\circ} /$ Libras II & 41 & 35 \\
\hline 7\%/Libras III & 37 & 31 \\
\hline $8^{\circ} /$ Libras IV & 17 & 14 \\
\hline
\end{tabular}

Fonte: Dados da Pesquisa, 2016.

$\mathrm{Na}$ tabela 02, explicitam-se as opiniões dos graduandos acerca da importância de aprender a Libras e como as aulas eram facilitadas. Um percentual predominante de $99 \%$ dos graduandos de Enfermagem desta IES acham de extrema importância a disciplina de Libras durante o seu curso, integrante da matriz de forma obrigatória.

Das opiniões, demonstrou-se que $71 \%$ não conheciam Libras antes de estudar na IES, com um número considerável de interações positivas (87\%). Quanto ao uso de materiais inovadores em sala de aula, somando às abordagens (textual, slides, 
teatros e vídeo aulas) utilizadas, $76 \%$ verificam uma desenvoltura inovadora do docente para facilitação de suas aulas. Ademais, o nível de alcance das expectativas nesta disciplina foi demonstrado de forma satisfatória (87\%).
Já em relação a esses graduandos aperfeiçoarem-se em Libras após formados, nota-se que $63 \%$ procuraram outra forma de se especializarem no processo comunicacional com os surdos.

Tabela 02 - Opiniões dos Graduandos sobre a Importância em Aprender Libras e o como era Facilitada a Disciplina. Maceió - AL, Brasil

\begin{tabular}{|c|c|c|}
\hline Questionamentos/Respostas & $\mathbf{N}^{\circ}$ & $\%$ \\
\hline \multicolumn{3}{|c|}{ Você acha importante que os graduandos de Enfermagem estudem Libras? } \\
\hline Sim & 118 & 99 \\
\hline Não & 01 & 01 \\
\hline \multicolumn{3}{|c|}{ Você conhecia Libras antes de estudar na IES? } \\
\hline $\operatorname{Sim}$ & 35 & 29 \\
\hline Não & 84 & 71 \\
\hline \multicolumn{3}{|c|}{ Você enfrentou dificuldades na interação com o professor de Libras? } \\
\hline Sim & 15 & 13 \\
\hline Não & 104 & 87 \\
\hline \multicolumn{3}{|c|}{ Quais foram os recursos adotados pelo professor na condução das aulas? } \\
\hline Textual & 02 & 02 \\
\hline Slides/explorativas & 27 & 23 \\
\hline Vídeo aulas & 12 & 10 \\
\hline Teatro & 02 & 02 \\
\hline 3 ou 4 alternativas & 60 & 50 \\
\hline 2 alternativas & 16 & 13 \\
\hline \multicolumn{3}{|c|}{ A disciplina de Libras atendeu as suas expectativas como graduando? } \\
\hline Sim & 103 & 87 \\
\hline Não & 16 & 13 \\
\hline \multicolumn{3}{|c|}{ Quando você acabar a sua graduação você pretende se aperfeiçoar em Libras? } \\
\hline $\operatorname{Sim}$ & 75 & 63 \\
\hline Não, acho que já é suficiente & 41 & 34 \\
\hline Não, não acho importante & 03 & 03 \\
\hline
\end{tabular}

Fonte: Dados da Pesquisa, 2016.

Para os questionamentos relacionados diretamente com o objeto de estudo em relação à Libras, observou-se que cerca de $71 \%$ dos Graduandos em Enfermagem não conheciam Libras antes de estudar na IES.

A Tabela 03 relacionou as opiniões acerca de que os mesmos sentiam-se preparados para atender o paciente surdo, demonstrando-se que a soma dos que estão preparados para atender algum surdo (22\%) com os que não sabem responder (34\%) chega a um número considerável de $56 \%$. Há também os somatórios das respostas sobre já ter atendido algum surdo (32\%) com a resposta da indagação se outro profissional prestou atendimento (57\%), chegando a uma porcentagem de $89 \%$. 
Tabela 3: Opiniões dos Graduandos sobre a sua Possível Relação de Atendimento ao Surdo. Maceió - AL, Brasil

\begin{tabular}{lll}
\hline Questionamentos/Respostas & $\mathbf{N}^{\circ}$ & $\mathbf{\%}$ \\
\hline Você acha que está preparado para atender um surdo? & 26 & 22 \\
Sim & 52 & 44 \\
Não & 41 & 34 \\
Não sei responder & & \\
Você já atendeu algum surdo nos seus estágios? & 38 & 32 \\
Sim & 81 & 68 \\
Não & & \\
Soube de alguém (outro profissional) que passou por esta situação? & 68 & 57 \\
Sim & 38 & 32 \\
Não & 13 & 11 \\
Não sei responder & & \\
& & \\
\hline
\end{tabular}

Fonte: Dados da Pesquisa, 2016.

\section{DISCUSSÃO}

A prevalência dos Graduandos em Enfermagem no turno noturno e possuírem vínculos empregatícios, ou seja, serem trabalhadores, sugere o acesso ao nível superior que, neste estudo, foi por intermédio de uma IES privada, resultando em necessidade de provimento de renda para suprir as necessidades da própria graduação. Percebe-se que é comum graduandos de enfermagem apresentarem vínculo empregatício durante sua formação profissional:

"Embora com dupla jornada de atividades, a maioria dos sujeitos avalia como satisfatória suas condições de vida e saúde, independente da distribuição do tempo, pois relatam saúde, situação financeira estável e admitem conseguir conciliar a profissão com os estudos e tarefas familiares (...) Observou-se que não só motivados pelo saber é que os trabalhadores buscam a graduação, mas também pelo desejo de melhores condições de trabalho e salários, pois, na medida em que evoluem na construção do conhecimento, têm perspectivas de mudança do padrão financeiro, o que demonstra coragem e determinação na busca de seus objetivos, considerando-se que é árdua a batalha de estudar e trabalhar ${ }^{15}$."

As opiniões encontradas neste estudo demonstram importância em receber o conhecimento da disciplina de Libras, reafirmando-se que Libras é a linguagem pela qual o surdo expressa-se, e os profissionais da saúde necessitam estudá-la para ter uma comunicação de qualidade nas consultas de saúde. ${ }^{16}$ A comunicação com o Surdo é indício de promoção de uma assistência humanizada e propícia para esses pacientes. ${ }^{6}$

$$
\text { Problemas de comunicação }
$$
interpessoal estão presentes em todo sistema de saúde e tornam-se mais significantes quando englobam barreiras de linguagem e cultura $^{5}$, tornando-se 
indispensável às equipes de saúde a busca por novos conhecimentos para atender às necessidades de sua clientela, facilitando a interação e visando à promoção de um atendimento mais humanizado. ${ }^{17}$

O perfil dos enfermeiros egressos vem passando por metamorfoses ao longo dos anos, pois sua trajetória vem conectada ao modelo socioeconômico e político vigente do país. Nela, este caminho foi caracterizado de forma heterogênea, encontrando desafios que foram superados nos limites conjunturais da sociedade. As IES de enfermagem têm o dever de ser exemplo de boas práticas, começando pelo respeito integral pela pessoa humana,

\section{CONCLUSÃO}

A disciplina de Libras de forma obrigatória na matriz curricular da IES teve impacto positivo na visão dos discentes, algo de suma importância para a sua formação profissional, pois esses, em sua maioria, tiveram o primeiro contato com a disciplina na IES e, em algum momento de sua graduação, já precisaram se comunicar com algum surdo utilizando a sua língua mãe, compreendendo a emissão comunicacional do surdo.

Em relação ao facilitador de Libras na IES, a maior parte dos graduandos afirmou não possuir problemas no processo de ensino e aprendizagem, pois as aulas são trazendo, com isso, integração e verdadeiras experiências clínicas simuladas nos seus currículos. ${ }^{18}$

A preferência pelo atendimento por profissionais que conhecem Libras garante a independência e privacidade. ${ }^{19}$ As pessoas surdas que procuram os serviços de saúde buscam, além de acolhimento, que sejam mantidos os princípios de confidencialidade, gerando relações de confiança com os profissionais para poder resolver seu problema de saúde ${ }^{20}$. Com a aquisição do conhecimento em Libras em seu processo formativo, os graduandos garantem maior suporte no atendimento ao deficiente auditivo.

dinâmicas e interativas, expositivas, musicadas e teatrais, mas sugere a necessidade de a IES ofertar estágios com surdos na vivência de sala de aula, tendo, com isso, uma experiência de vivenciar LIBRAS junto com os surdos e não com ouvintes. Ficam claras a relevância e a importância da disciplina de Libras durante o processo formativo dos discentes de enfermagem.

Ademais, tal objeto traz, ainda, como fator limitante o reduzido número de publicações, evidenciando a escassez de pesquisas que abordassem tal temática com enfermeiros e o próprio delineamento metodológico. 


\section{REFERÊNCIAS}

1. Presidência da República (Brasil). Constituição da República Federativa do Brasil de 1988. Emendas Constitucionais de Revisão [Internet]. Brasília, DF: Presidência da República; 1988 [citado em 10 jan 2017]. Disponível em:

http://www.planalto.gov.br/ccivil_03/const ituicao/constituicaocompilado.htm

2. Presidência da República (Brasil). Lei 8080, de 19 de setembro de 1990.

Dispõe sobre as condições para a promoção, proteção e recuperação da saúde, a organização e o funcionamento dos serviços correspondentes e dá outras providências [Internet]. DOU, Brasília, DF, 20 set 1990 [citado em 10 jan 2017]. Disponível em:

http://www.planalto.gov.br/ccivil_03/leis/L 8080.htm

3. Dantas TRA, Gomes TM, Costa TF, Azevedo TR, Brito SS, Costa KNFM. Comunicação entre a equipe de enfermagem e pessoas com deficiência auditiva. Rev. Enferm UERJ. [Internet]. 2014 [citado em 10 jan 2017]; 22(2):16974. Disponível em: http://www.facenf.uerj.br/v22n2/v22n2a04 .pdf

4. Silva RP, Almeida MAPT. Relação comunicativa entre o profissional de saúde e os surdos: uma revisão bibliográfica. Id On Line Rev Multidisc Psicol. [Internet]. 2017 [citado em 2 abr 2019]; 11(37):65369. Disponível em:

https://idonline.emnuvens.com.br/id/article /view/868/1229

5. Pires HF, Almeida MAPT. A percepção do surdo sobre o atendimento nos serviços de saúde. Rev Enferm Contemp. [Internet]. 2016 [citado em 20 jan 2017]; 5(1):68-77. Disponível em: https://www5.bahiana.edu.br/index.php/enf ermagem/article/viewFile/912/650

6. Marques RS, Pereira RMP. Acessibilidade dos surdos: formação dos profissionais da enfermagem em
Itumbiara/GO. Rev Vale: arte, ciênc cult. [Internet]. 2017 [citado em 02 abr 2019]; 9(1):162-72. Disponível em:

http://www.fema.edu.br/images/revistavale /revista9.pdf\#page $=160$

7. Soares IP, Lima EMM, Santos

ACM, Ferreira CB. Como eu falo com você? a comunicação do enfermeiro com o usuário surdo. Rev Baiana Enferm.

[Internet]. 2018 [citado em 13 mar 2019]; 32:e25978. Disponível em:

https://rigs.ufba.br/index.php/enfermagem/ article/view/25978

8. Silva PS, Basso NAS, Fernandes

SRCM. A enfermagem e a utilização da língua brasileira de sinais no atendimento ao deficiente auditivo. Rev UNINGÁ Rev. [Internet]. 2014 [citado 10 Jan 2017]; 17(1):5-12. Disponível em: http://www.mastereditora.com.br/periodico /20131231_171804.pdf

9. Carvalho Filha FSS, Silva SR, Lando GA. Cuidado ao surdo: conexões com o direito à saúde. Rev Ciênc Saberes [Internet]. 2015 [citado em 02 abr 2019]; 1(1):31-38. Disponível em: http://www.facema.edu.br/ojs/index.php/R eOnFacema/article/view/17/9

10. Presidência da República

(Brasil). Lei n ${ }^{\circ} 10.436$, de 24 de abril de 2002. Dispõe sobre a Língua Brasileira de Sinais - Libras e dá outras providências [Internet]. DOU, Brasília, DF, 25 abr 2002 [citado em 14 jan 2017]. Disponível em: http://www.planalto.gov.br/ccivil_03/leis/2 002/L10436.htm

11. Presidência da República (Brasil). Lei $n^{\circ} 10.098$, de 19 de dezembro de 2000. Estabelece normas gerais e critérios básicos para a promoção da acessibilidade das pessoas portadoras de deficiência ou com mobilidade reduzida, e dá outras providências [Internet]. DOU, Brasília, DF, 20 dez 2000 [citado em 14 jan 2017]. Disponível em: http://www.planalto.gov.br/ccivil_03/leis/L 10098.htm

12. Senado Federal (Brasil). Língua brasileira de sinais "Uma Conquista 
Histórica”. Brasília, DF: Senado Federal; 2006 [citado em 14 jan 2017]. Disponível em:

http://www.artelibras.com.br/ewadmin/do wnload/Lingua_Brasileira_de_Sinais_Uma _Conquista_Historica.pdf

13. Presidência da República (Brasil). Decreto n ${ }^{\circ} 5.626$, de 22 de dezembro de 2005. Regulamenta a Lei $\mathrm{n}^{\circ}$ 10.436, de 24 de abril de 2002, que dispõe sobre a Língua Brasileira de Sinais Libras, e o art. 18 da Lei ${ }^{\circ} 10.098$, de 19 de dezembro de 2000. DOU, Brasília, DF, 23 dez 2005 [citado em 13 jan 2017].

Disponível em:

http://www.planalto.gov.br/ccivil_03/_Ato 2004-2006/2005/Decreto/D5626.htm 14. Rodrigues $\mathrm{CH}$, Beer H. Direitos, políticas e línguas: divergências e convergências na/da/para educação de surdos. Educ Real. [Internet]. 2016 [citado em 16 Dez 2017]; 41(3):661-80.

Disponível em:

http://www.scielo.br/scielo.php?script=sci _arttext\&pid=S2175-

$62362016000300661 \& \operatorname{lng}=$ pt\&nrm=iso

15. Giustina FPD, Carneiro DMD,

Souza RM. A enfermagem e a deficiência auditiva: assistência ao surdo. Rev Saúde Faciplac. [Internet] 2015 [citado em 02 abr 2019]; 2(1):03-18. Disponível em: http://revista.faciplac.edu.br/index.php/RS F/article/view/101/57

16. Dias A, Coutinho C, Gaspar D, Moeller L, Mamede M. Libras na formação médica: possibilidade de quebra da barreira comunicativa e melhora na relação médico-paciente surdo. Rev Bras Educ Méd. 2017 [citado em 16 dez 2018]; 96(4):209-14. Disponível

em: https://www.revistas.usp.br/revistadc/a rticle/view/131619

17. Vieira CM, Caniato DG, Yonemotu BPR. Comunicação e acessibilidade: percepções de pessoas com deficiência auditiva sobre seu atendimento nos serviços de saúde. RECIIS. [Internet]. abr/jun 2017 [citado em 18 jul 2017]; 11(2):1-12. Disponível em: https://www.reciis.icict.fiocruz.br/index.ph p/reciis/article/view/1139/2114

18. Lima ICS. Expansão dos cursos de enfermagem no nordeste: crescimento versus qualidade. Rev Interdisc. [Internet]. 2016 [citado em 16 dez 2017]; 9(4):14248. Disponível em: http://revistainterdisciplinar.uninovafapi.ed u.br/index.php/revinter/article/view/802 19. Saraiva FJC, Moura RS, Tavares NVS, Lucena Junior B, Santos IS, Santos RFM. O Silêncio das mãos na assistência aos surdos nos serviços de saúde brasileiros. Olhares Plurais [Internet]. 2017 [citado em 19 jan 2017]; 13(2):94-104. Disponível em: http://revista.seune.edu.br/index.php/op/art icle/view/283.

RECEBIDO: $30 / 06 / 18$

APROVADO: 06/05/19

PUBLICADO: 07/19 